Brit. J. industr. Med., 1949, 6, 144.

\title{
AN OUTBREAK OF CASES OF RAYNAUD'S PHENOMENON OF OCCUPATIONAL ORIGIN *
}

\author{
BY \\ JOHN N. AGATE \\ From the Department for Research in Industrial Medicine (Medical Research Council), \\ The London Hospital
}

(RECEIVED FOR PUBLICATION, APRIL 27, 1949)

\section{INTRODUCTION}

Vascular disturbances resulting from the handling of mechanical devices have been recognized since 1911, when Loriga described a case which followed the use of a pneumatic tool. Then Alice Hamilton and others (1918) described, in a long monograph, an outbreak amongst the stonecutters-of Louisiana who also used such tools. Pneumatic hammers and chisels have been blamed for most of the cases up to 1945, though Middleton (1930) observed Raynaud's phenomenon in men exposed to intense vibration while working at "pounding-up" machines in the boot and shoe industry. The literature up to 1945 has been summarized in the papers of Hunter, McLaughlin, and Perry (1945), and Agate and Druett $(1946,1947)$. Up to that time it had been recognized that the harmful processes were those which subjected the workers' hands to repeated hammer blows, and there was much debate as to which were the most harmful tool speeds. No other mechanical tools had yet been found harmful.

In January, 1945, a Trades Union representative in a large Manchester engiheering works sought advice about an outbreak of cases of intermittent blanching of the fingers which had already earned the unfortunate name of "dead hand." There could be no doubt from the description that these cases were examples of Raynaud's phenomenon. But the men and women concerned were working neither with pneumatic tools nor pounding-up machines. A start was, therefore, made with clinical and experimental investigations in the hope of finding out the natural history and the ætiology of this outbreak of disease. The experimental work, dealing with the nature of the vibration set up by these tools in comparison with other vibratory tools, has been published previously in this

\footnotetext{
* This material formed part of a thesis accepted for the M.D.
}

journal (Agate and Druett, 1947). At the same time Telford and others became interested in the problem at this factory, and in 1945 they published a report on the first thirty-four cases they saw. Meanwhile the present investigation continued. It was designed to include a greater number-as many of the workers at risk as possible - and to follow them up over a period. Most of Telford's thirty-four individuals volunteered for a second and independent examination, and will be considered here with the rest.

While this work was going on, the writer, with Druett and Tombleson (1946), also investigated a small outbreak of Raynaud's phenomenon in a group of thirty-seven grinders of small metal castings. Thirty-two were found to be affected. These grinders were all working at large belt-driven wheels mounted in fixed bearings; they pressed small castings against these wheels, and intense vibration was set up. This small outbreak provided confrmation of the view that the chief cause of the disorder is vibration, whether this be set up by hammer-like blows, by rotary hand tools, or by friction at a grinding surface. Gurdjian and Walker (1945) had already described the cases of six women who contracted the same disorder while using small pneumatic hammers for constructional work on aircraft; but they were affected in the hand which held the object to be riveted, not the hand which held the hammer.

\section{Definition}

It is now recognized that Maurice Raynaud included amongst the cases he described in his thesis of 1862 examples of several different diseases in which the same manifestations had appeared. At the present time it is usually accepted that the term " Raynaud's disease" shall be used only for a distinct but rare symmetrical vascular disorder of unknown ætiology, which is found mostly in 


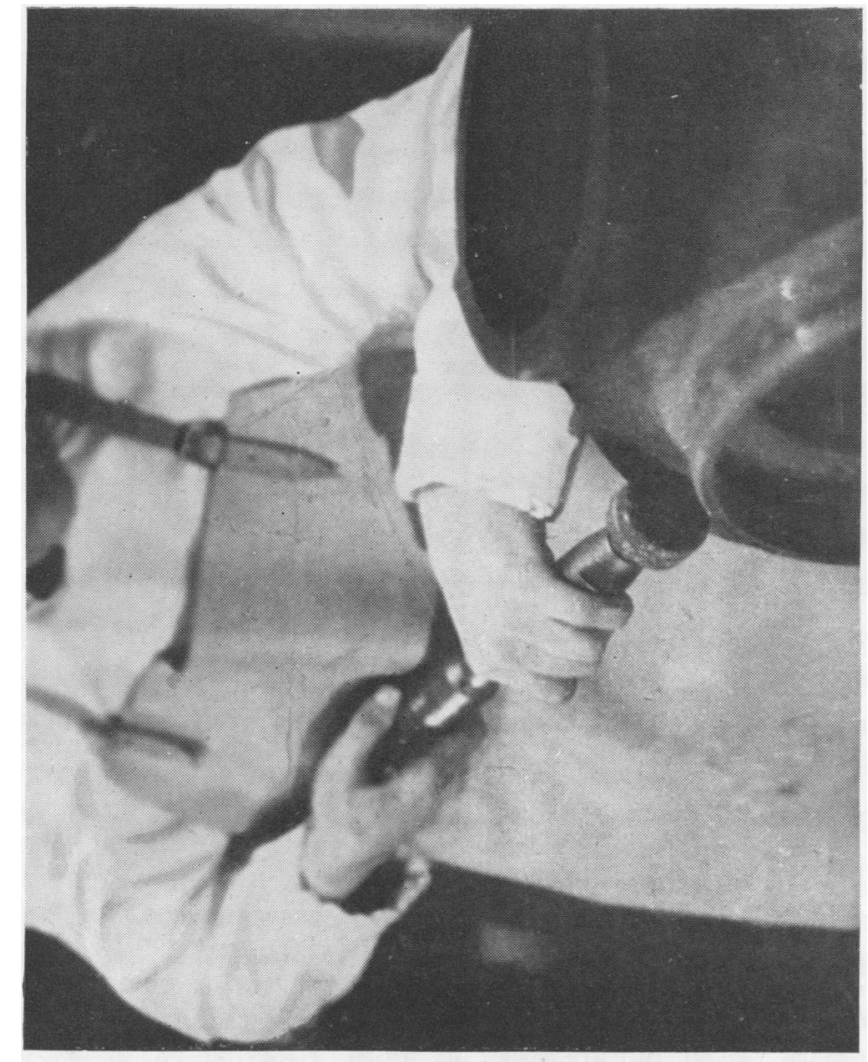

145
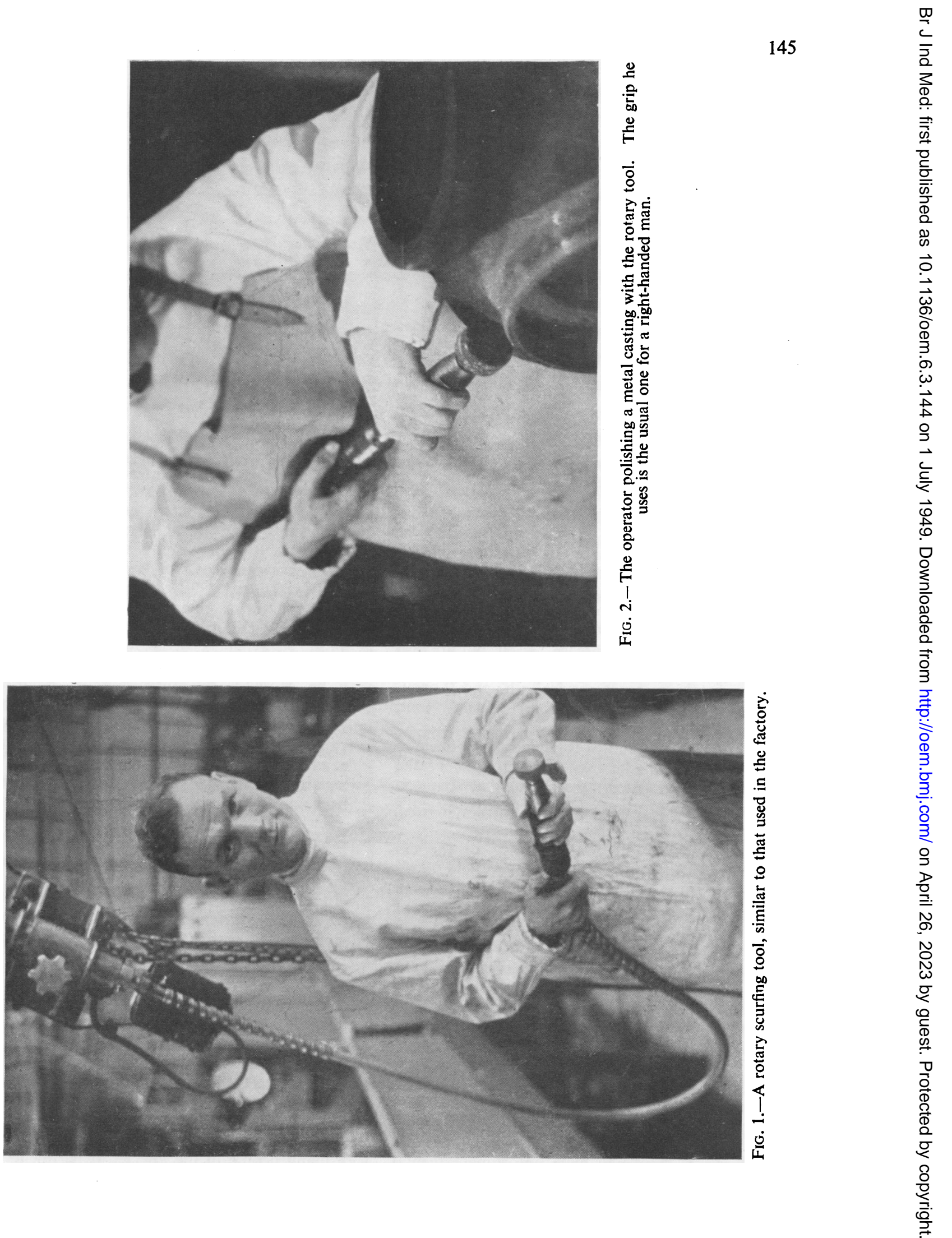


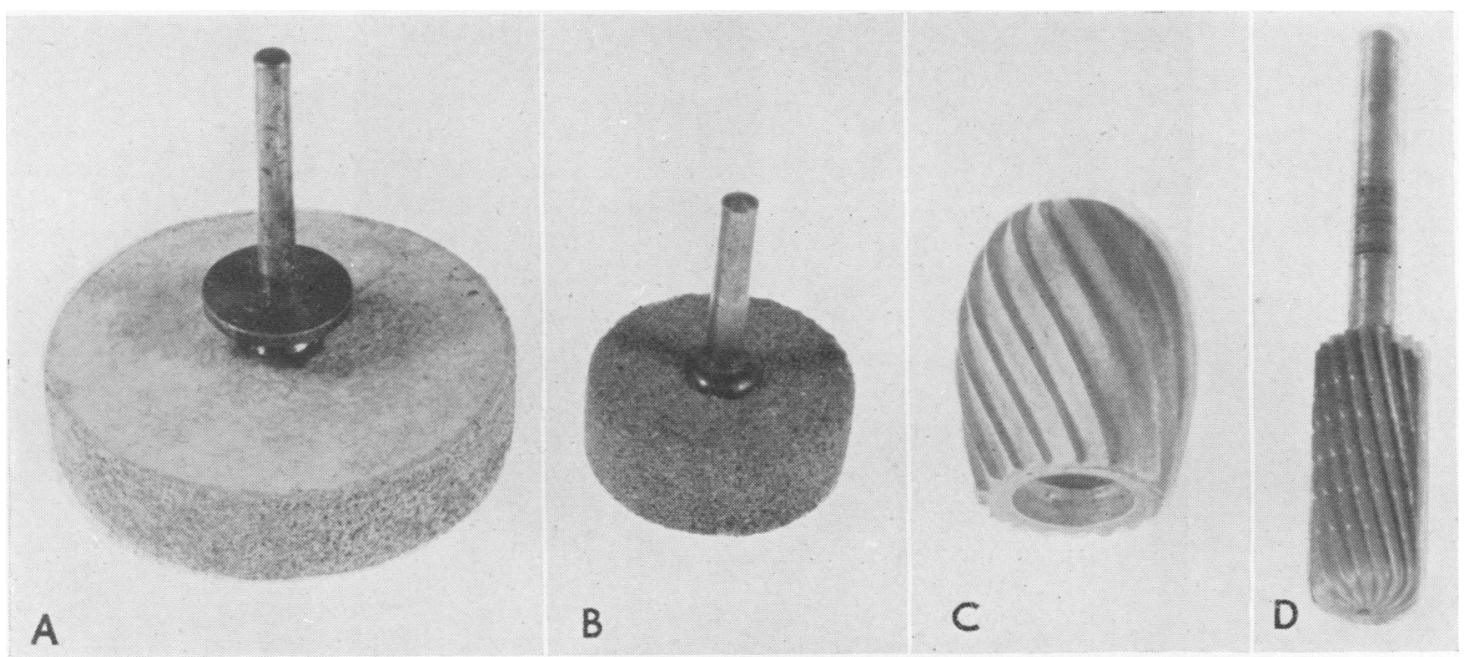

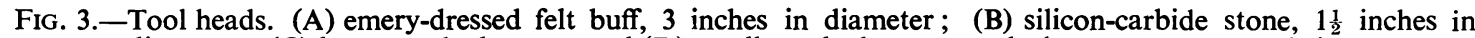
diameter; (C) large-toothed cutter, and (D) small-toothed cutter, each three-quarters actual size.

young women; similarly, that "Raynaud's phenomenon" shall apply to a symptom or sign, namely, intermittent pallor or cyanosis of the extremities. Hutchinson (1901) advocated the use of the latter term and suggested it should be qualified whenever the ætiology was known. The colour changes of "Raynaud's phenomenon" do occur in cases of " Raynaud's disease" itself, but are also to be seen in such conditions as hereditary cold fingers, certain cases of cervical rib, and " pneumatic hammer disease," amongst others (Hunt, 1936).

The clinical definition of Raynaud's phenomenon given by Hunt will be used here, in spite of the opinion of Allen and others (1946) that it is too narrow for all purposes. Hunt defined Raynaud's phenomenon as :

"Intermittent pallor or cyanosis of the extremities precipitated by exposure to cold, without clinical evidence of blockage of the large peripheral vessels and with nutritional lesions, if present at all, limited to the skin."

\section{Nomenclature}

The following synonyms are to be found in the accounts already published : " dead hand " (Telford and others, 1945; Biden-Steele and King, 1947) ; " dead fingers"; "white fingers" (Hamilton and others, 1918); " pneumatic hammer disease" (Mills, 1942); “pseudo-Raynaud's disease" (Brocklehurst, 1945) ; " traumatic vasospastic disease of the hand" (Gurdjian and Walker, 1945). The first three of these are graphic, but are wanting in accuracy: they may have unfortunate mental associations for the sufferers, and their use cannot be defended. The term "pseudo-Raynaud's disease" seems to add nothing to an understanding of the disease and can have no more claim to be used than the name "Raynaud's disease" itself, which has been excluded by definition. BidenSteele and King (1947) appeal for the abandonment of both "Raynaud's disease" and "Raynaud's phenomenon" on the ground that legal confusion may be caused; but these authors themselves confuse the meanings of the two terms, and have only suggested "dead hand" as an alternative. "Traumatic vasospastic disease" defines the probable ætiology and disorder of function, but has been used by only one author. The name " pneumatic hammer disease," at one time specific, must be considered outmoded in the light of recent experiences.

"Raynaud's phenomenon" is a widely accepted descriptive term, and it is suggested that all vascular disorders of the type under review might best be included within the single diagnosis of "Raynaud's phenomenon of occupational origin," at least until the factors in their causation are all understood. In nearly every case vibration will be found to be the principal factor.

\section{The Present Outbreak}

The 1939-45 war had brought fresh kinds of employment to the locality. The engineering works in which the outbreak occurred was a large new one built for war purposes : it absorbed workers from the less essential industries in the district. Therefore many people in the affected departments had 
found themselves in an engineering trade for the first time in their lives, and many were already middle-aged. Most of them expected to return to their old peace-time jobs in due course. In the meantime their work consisted of "scurfing" or "polishing" metal castings with rotary hand tools, in the use of which they had had to be specially trained. The working conditions and wages for this job were good. The factory was light, airy, and always sufficiently warm. Excellent medical and welfare departments were maintained, and there were two full-time medical officers. The latter, when consulted about the vascular disturbance, had advised a change of job for those affected and warned the management accordingly. Nevertheless the workpeople had considerable misgivings as to their future working capacity and the permanent effects which this disease might have on their fingers. With the war coming to a close, they also feared they would be declared redundant. Therefore, because of their misgivings, these workers had themselves asked for an investigation to be done, and their willingness to come forward made it possible for nearly all these at risk to be interviewed and examined-a rare enough happening in industrial medical investigations. The management, anxious to determine the extent of the outbreak and to discover preventive measures, were willing for a detailed investigation to take place on the premises. Their laboratory staff had begun experiments to try to reduce tool vibration, but without notable success.

\section{The Tool in Use}

More than three hundred men and women in two separate shops were engaged in polishing and grinding castings made either of steel or a " duralumin " type of alloy. The process is also known as "dressing" or " scurfing." For the purpose they used a portable rotating tool which could be adapted to various types of work (fig. 1). It consisted of an electric motor of $\frac{1}{2}$ or 1 horse power suspended from an overhead girder or placed close at hand on the bench : to this was attached a flexible cable, about five feet in length, made up of a central rotating core of thick wire enclosed in a flexible spiral steel covering which was attached to the motor casing. The torque of the motor was transmitted through a system of pulleys by which three different speeds were made possible, that is, approximately 1,220 revolutions per minute (r.p.m.), 2,960 r.p.m., and 7,700 r.p.m. In general, the heavier the work, the lower the speed that was used. At the other end of the cable was a tubular steel hand-piece of about $1 \frac{1}{2}$ inches diameter. Its outer casing was attached to the spiral outer covering of the cable and was of convenient size to hold in the hands. Within it a central spindle connected to the core of the cable was free to rotate on three, or sometimes four, sets of ball bearings. The spindle carried a chuck into which various cutting and polishing tools or " heads" could be fixed at will.

Such a tool is ideally suited to polishing the various surfaces of a complex casting, and much of the work could not have been done in any other way. The operatives stood at a bench all through a shift, with the motor of the tool suspended above and behind them. A right-handed man would have it at his right shoulder, the cable passing under his right axilla without touching it, and across his forearm from medial to lateral side ; the proximal end of the handpiece rested in the palm of the supinated right hand. This hand, gripping firmly, steadied the tool and the cable, but the real work and the guiding of the tool would be done by the left hand grasping the distal end of the handpiece with a firm grip just over the chuck, so that the dorsum of the hand was uppermost with the forearm in a pronated position (fig. 2). By this means a strong downwards pressure could be exerted and a side-to-side sweeping action used. Occasionally the cable was passed over the shoulder and an " overhand" grip was used with both hands, though the left would still be nearest the head of the tool. The grip in the case of a left-handed man was usually reversed, with the right hand in front nearest to the head.

In the smaller shop steel crankshafts were being polished. This process was also known as "glazing." For the preliminary rough work $1 \frac{1}{4}$-inch silicon carbide stones on $\frac{1}{4}$-inch spindles were mounted in the chuck, but for the finer polishing felt " buffs," three inches in diameter, coated with glue and abrasive powder were preferred. Only quite a light stroke was needed to burnish the metal, and only the higher speeds were used. It was generally considered that little vibration was set up in these conditions.

The larger department was for the scurfing of duralumin engine castings. Certain broad surfaces were polished by a variety of emery-dressed buffs, mops, abrasive paper discs, and circular wire brushes, but much the greater part of the work consisted in cutting off surplus metal by means of rotary toothed cutters (fig. 3). Duralumin is of great strength, but it is not very hard, and at slow speeds with suitable cutters a 1 -inch thickness of redundant metal can easily be removed by this rotary tool. Cutters vary from 1 to 1 inch in diameter and usually have coarse teeth cut in a spiral. An intense vibration is always set up, and a powerful, sustained grip is needed. It is all that a novice can do to hold the tool in position to do the cutting. 
The heaviest scurfing work in this factory was usually given to men, but this was not an invariable rule. Sometimes the shape of the casting was such that a number of sizes of cutters had to be used in succession, so that one operator would use a variety of heads in the course of a day. This fact made assessment of the relative importance of each in the production of symptoms a very difficult matter. But at one critical stage of the war an increased output was called for, and a production line was set up. Each worker on this line then did a limited piece of the work and pushed the casting along on rollers to his neighbour without himself having to change cutters. Some of the men were, therefore, obliged to use the larger cutters continuously ; this made comparisons between the " heads" somewhat easier for the clinician to draw, but was probably not in the individual's best interest, because the largest cutters seemed to produce the severest vibration, as will be shown later. The general increase in tempo of the work at this time was blamed by a number of workers as being the immediate cause of their symptoms : certainly it should be considered an aggravating factor in the ætiology.

It is of importance to note that the handpiece of the tool was warm except when work first began in the morning or after a break; also that the interchangeable cutting and polishing heads were mounted on slender spindles, some of which were several inches long. It was possible for even the shortest of them to be knocked out of alignment. The workers were not trained mechanics and, therefore, would not instinctively correct the alignment ; indeed, by so doing they would feel that they were losing precious time.

\section{THE NATURE AND INCIDENCE OF THE DISORDER : INITIAL FINDINGS}

In March, 1945, as many as possible of those who were using the rotating polishing tool, or who had recently given up using it, were interviewed. It was not possible to include any who had already left the firm. A total of 293 workers were seen, of whom forty-seven were women. According to the records made available by the factory personnel department, some thirty to thirty-five other people were also employed in this way, but they had to be missed on account of sickness, leave of absence, or changes of shift. It so happened that most of these were men who usually worked on the largest castings of all : they belonged to the group in which the incidence of vascular disturbances proved to be highest. If, therefore, these thirty or thirty-five individuals could have been interviewed it is likely that the incidence of Raynaud's phenomenon would have been even higher than it is shown to be by the figures which are available.

Each subject was asked to give a full occupational history from the time of leaving school, so that any who had previously used pneumatic hammers or had done grinding or similar work could be set apart. A general medical history was taken, and a full physical examination followed. Etiological factors other than present occupation could thus be eliminated at the start. Finally, as a rough clinical test, each person was asked to sit with his or her hands immersed above the elbows in a trough of running water at $15^{\circ} \mathrm{C}$. After 15 minutes the hands were dried and examined for visible confirmation of any claims of colour changes.

Of the original 246 males, thirteen were excluded because they had previously been subjected to vibration in earlier occupations. Of these, four had handled pneumatic tools, two had been " holders up " for riveters, six had worked at grindstones, and one had used some sort of rotating scurfing tool elsewhere under conditions difficult to define.

There remained 233 males to be considered, of whom 163 (69.9 per cent.) were judged to be suffering from attacks of Raynaud's phenomenon by that time.

Two of the forty-seven women were excluded, one because she had done grinding work, and the other because she had clearly been suffering from true Raynaud's disease even before she had started work. Of the forty-five who remained, twenty-one (47 per cent.) were judged to be suffering from attacks of Raynaud's phenomenon.

These figures suggest that in March, 1945, the incidence of Raynaud's phenomenon amongst those exposed to risk was at least 184 out of 278 , or 66.2 per cent. In every one of these cases the vascular disorder had first appeared after using the portable tool in question. Without doubt, therefore, it should be considered of occupational origin.

All the initial interviews were conducted during March and April, at the close of a moderately severe winter. It is necessary to record this fact, since the prevalent air temperature undoubtedly affects the severity of symptoms. Those who were questioned must have had in mind their recent experience of the cold weather, and they should easily have been able to recall a symptom such as blanching of the fingers, which in so many cases was brought on by it. Their answers might have been less informative if given at the end of the summer, at which time the less severely affected ones could have forgotten their symptoms or even have claimed to be cured. Notice must always be taken of the time of the 
year, particularly when investigating the course of this disease.

The diagnosis had in many cases to be made on the history, and often on this alone. So great a reliance on history may be criticized, on the ground that the workpeople in this factory had little to lose, and indeed might have much to gain, by claiming symptoms. Indeed, their natural anxieties might have led to some involuntary distortion of the testimony. Nevertheless it was possible to test the validity of claims by cross examination. Selfcontradictory histories were not encountered. The cold water immersion test in many cases confirmed the presence if not the extent of the lesion. In cases where it did not, the factory medical officer was sometimes able to say he had seen vascular disturbances on another day. The follow-up study more than confirms the high incidence of the condition.

Age Distribution.-It is necessary to determine the age distribution for both the affected and the unaffected workers lest this factor should have a bearing on the case incidence. Table 1 shows this distribution for males and females separately, and for the aggregate.

It appears that the age distribution is fairly comparable in the affected and unaffected groups. The age-group 40 to 49 (into which the greatest number of workers fell because of the nature of the labour force available) comprises a somewhat disproportionate number of affected men, it is true, but this high proportion is not seen in the next oldest group and may therefore be fortuitous. Amongst the women the highest relative incidence of disease is in the age-group 20 to 29 , but the numbers are too small for any conclusion to be drawn from this. It is clear from Table 1 that Raynaud's phenomenon due to the use of this particular tool is not confined to the older workers, as would have been expected had the phenomenon been directly related to the progressive vascular changes of advancing years.
Past History and Family History.-Particular enquiry was made for any past history of vascular disorders or "bad circulation." A few admitted to seasonal perniosis in one form or another, but none would say that they had ever noticed blanching of fingers even after sea-bathing, which is commonly a precipitating event in normal people who occasionally experience "deadness" of a finger. Only two out of the whole series knew of such blanching in other members of their families.

It was unexpected to find so few giving a positive history in these respects. Lewis and Pickering (1934) contended that a positive earlier history could be obtained from 25 per cent. of normal men and 30 per cent. of normal women, and that, of these, 50 per cent. could be expected to give a positive family history. They also found that such attacks were usually experienced in youth. It may be that the older people in the present series had forgotten such minor occurrences. Otherwise these negative findings can only be explained as a local variation or as an involuntary distortion of the facts because of anxiety about the immediate symptoms. The latter is the more understandable explanation.

Symptoms.-The common complaint was of numbness or " deadness," or that there, were from time to time changes of colour in the fingers, extending proximally from the tips. One or two of the men first affected in this outbreak had also complained that their fingers became "locked" round the handpiece and could be freed only by passively straightening the fingers with the disengaged hand. Particular watch was kept for this latter symptom because it had been reported by the Trades Union representative and was considered likely to cause accidents. Only two men appeared definitely to have experienced it, while two other men and two women were doubtful. Several men talked of " a continuous ache" in the muscles of the ulnar border of the forearm, coincident with the blanching of the

TABLE 1

TO SHOW THE AGE DISTRIBUTION FOR AFFECTED AND UNAFFECTED WORKERS

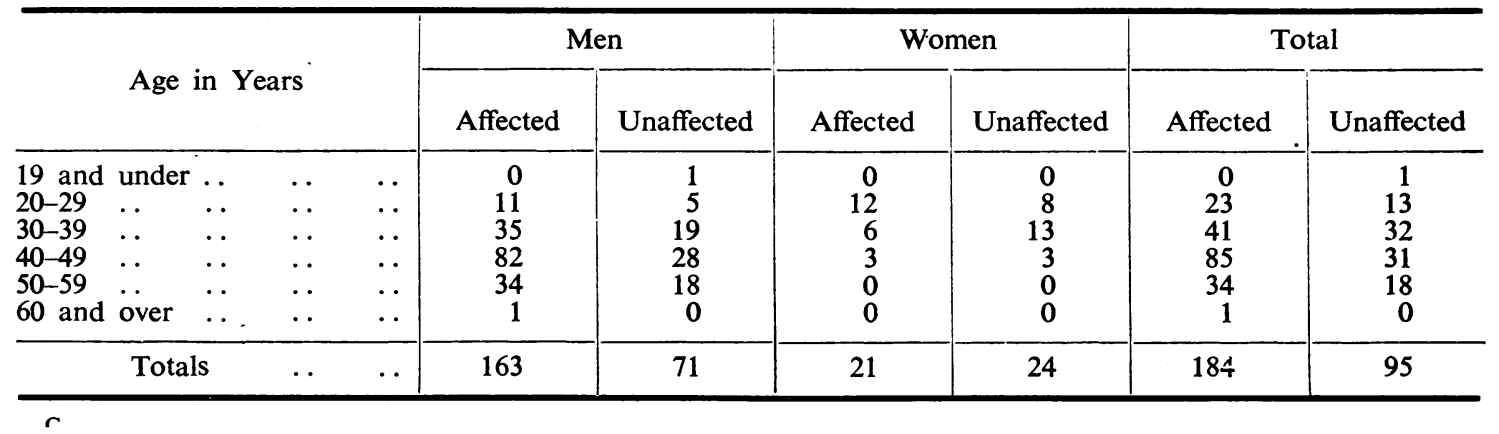


fingers. This appeared to be in the nature of ischæmic cramp, but it was too ill-defined to be of help in localizing the actual site of a vascular lesion.

The Effect of Cold.-The relationship of the blanching and numbness to cold was very definite. Usually this information was volunteered, and early rising in winter or washing in cold water were both held particularly responsible. Altogether $145(89$ per cent.) of the affected men and 14 (67 per cent.) of the affected women agreed that cold was the chief precipitating factor. Eleven people denied that it was of any significance, and the remainder were uncertain.

Provided that the workers could keep warm it was to be expected that they would not suffer attacks while at work, and that loss of time and wages would be small. In fact only twenty-six (16 per cent.) of the affected men and six ( 29 per cent.) of the women had ever experienced attacks while actually working. One or two claimed to have had attacks only when starting a shift, that is, when the tool was cold to the touch. One man found it necessary to grasp a nearby electric light bulb to put an end to the attack which he always had on arriving at work in the morning.

Other Symptoms. - Pain, apart from the forearm cramp already mentioned, was an unusual symptom ; but loss of sensation was always noticed during attacks, and many men complained that they dropped their morning papers at breakfast. None spoke of a loss of the ability to grip : without this ability their work could not have been attempted. Several had noticed attacks coming on when they were carrying heavy weights. Nearly all the workers were smokers, and the effect of tobacco, therefore, could not be judged.

"Handedness."-One hundred and fifty-seven of the 163 affected men were right-handed. This means that they usually held the tool with the left hand in front, nearest the cutting head, as has been described. Of these 157, 134 were first affected in the left hand, while eight were simultaneously affected in both. Only three men were left-handed, and they held the tool in the reversed position with the right hand in front of the left. Two of these three were affected first in the right hand, and one in the left. The three men remaining were ambidextrous and held the tool either way at will : two of them were affected first in the left hand and one in the right. The affected women were all righthanded : eighteen of them were initially affected in the left and three in the right.

Handedness is, therefore, of considerable significance. Using the natural handedness (or dominant hand) as the criterion, it will be seen that $154(83.6$ per cent.) were affected first in the contralateral hand, and twelve ( 6.5 per cent.) first in the ipsilateral. In other words, in 83.6 per cent. of cases the hand nearest to the cutting head was affected alone or first of the two. This suggests that it receives the most vibration.

Duration of Exposure to Risk.- - The average time elapsing between the start of scurfing work and the first appearance of symptoms was (for the 163 affected men) 23.5 months, but there was wide variation from a minimum of two months, to a maximum of four years. The average time in the

$$
\text { TABLE } 2
$$

DURATION OF SCURFING WORK REQUIRED TO PRODUCE THE FIRST SYMPTOM, COMPARED WITH THE AGES OF THE VICTIMS, MALES AND FEMALES BEING TAKEN TOGETHER

\begin{tabular}{|c|c|c|c|c|c|c|c|c|}
\hline \multirow[b]{2}{*}{$\begin{array}{c}\text { Age } \\
\text { (years) }\end{array}$} & \multirow[b]{2}{*}{$0-6$} & \multirow[b]{2}{*}{$7-12$} & \multicolumn{3}{|c|}{ Months of Work } & \multirow[b]{2}{*}{$31-36$} & \multirow[b]{2}{*}{$37-42$} & \multirow[b]{2}{*}{\begin{tabular}{|c}
43 \\
and \\
over
\end{tabular}} \\
\hline & & & $13-18$ & $19-24$ & $25-30$ & & & \\
\hline $20-29$ & & $\begin{array}{l}x \times \\
x \times \\
x \\
x\end{array}$ & $\mid \begin{array}{lll}x & x & x \\
x & x & x \\
x & x\end{array}$ & $x \times x$ & $x$ & $x$ & $x \times$ & $x$ \\
\hline $30-39$ & $\begin{array}{l}x \times x \\
x\end{array}$ & 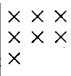 & $\mid \begin{array}{ccc}x & \times & \times \\
\times & \times & \times \\
\times & \times & \times\end{array}$ & 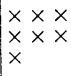 & $x \times$ & 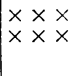 & $\mid \begin{array}{l}x \ddot{x} x \\
x \times\end{array}$ & $x$ \\
\hline $40-49$ & $x$ & $\begin{array}{ll}x & x \\
x & \times \\
x & \times \\
x & x \\
x & x\end{array}$ & 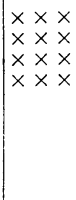 & \begin{tabular}{|lll}
$x$ & $\times$ & $\times$ \\
$\times$ & $\times$ & $\times$ \\
$\times$ & $\times$ & $\times$ \\
$\times$ & $\times$ & $\times$ \\
$\times$ & $\times$ & $\times$ \\
$\times$ & $\times$ & $\times$ \\
$\times$ & $\times$ & $\times$ \\
$\times$ & $\times$ & $\times$ \\
$\times$ & $\times$
\end{tabular} & $\begin{array}{lll}x & x & x \\
x & x & x \\
x & x\end{array}$ & $\begin{array}{lll}\times & \times & \times \\
\times & \times & \times \\
\times & \times & \times \\
\times & \times & \times \\
\times & \times & \times\end{array}$ & $\begin{array}{l}\times \times \times \\
\times \times \times \\
\times \times \times\end{array}$ & $x \times x$ \\
\hline $\begin{array}{c}50 \text { and } \\
\text { over }\end{array}$ & $\begin{array}{l}x \times x \\
\times x\end{array}$ & $\begin{array}{l}x \times x \\
x \times\end{array}$ & $\begin{array}{l}x \\
x\end{array}$ & $\begin{array}{l}x \times x \\
x \times\end{array}$ & $\begin{array}{l}x \times x \\
x \times x\end{array}$ & $\mid \begin{array}{l}x \\
x\end{array}$ & 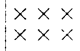 & $x$ \\
\hline
\end{tabular}

case of the affected women was 20.6 months, which is not appreciably different, and the limits were eight months and forty-five months. As many as thirty-three of these men and women had already suffered their first attack before they had completed a year of scurfing work. It had been tentatively suggested to the management of the factory that one year's service should be laid down as the maximum for any worker, but it is clear that this would by no means have solved the problem.

The distribution of cases by age and by duration of exposure to risk before the onset of symptoms can be seen at a glance, from Table 2. Duration of exposure to industrial hazards often goes hand in hand with age; but that was not the case in this factory because scurfing and polishing work had been introduced only recently, the training required was short, and the workers had been drawn from a mixed population of all ages.

The table shows a fair uniformity of distribution. There is a tendency for those in the youngest age 
group to have been exposed to risk for the shorter periods. In the age-group 40 to 49 years, where the majority of cases lay, the greatest number was in the exposure-period 19 to 24 months, that is, scattered round the mean exposure period for the whole group, men and women together. This was only to be expected. The distribution is remarkably uniform in the oldest age group. The general appearance of this Table suggests that when age is to be compared with severity of lesions or other variables, the effect of length of exposure can reasonably be ignored. The converse appears equally true.

Up to the time of the first enquiry the mean duration of employment on scurfing work for the workers who had not been affected was 25.7 months in the case of the men, but the time varied between one week and five years. In the case of unaffected women the mean was 24.8 months, the limits being one month to forty-six months. This " unaffected " group naturally contained newcomers, some of whom had obviously not had sufficient time to develop symptoms ; despite this, the mean exposure of the unaffected subjects was longer than the mean time taken to produce symptoms in the rest. Indeed, four of the unaffected group had worked longer than the maximum time so far taken to produce symptoms in anyone. Provided that other factors are equal, this suggests that there may be certain people who are insusceptible to the disease. The reason for such an insusceptibility is not easy to see, nor is it predictable in any individual case. A parallel can be drawn in other occupational diseases.

Anatomical Distribution of the Disorder.-Ninetytwo of the men and fifteen of the women had so far been affected in one hand only. The remainder (seventy-one and six respectively) had already had both hands involved, and the average total time of working before the disease became bilateral was 28.4 months for men and 25.7 for women. The second hand had become affected at any time up to twenty-four months after the first (mean $=.6 \cdot 6$ months) in the case of the men, and at any time up to twelve months after (mean $=7.5$ months) in the case of the women. As already stated, in fifteen cases the first signs were seen in both hands simultaneously.

In spite of the large number of diseases with which Raynaud's phenomenon is associated-and Hunt (1936) lists sixteen-any ætiological factor which might be common to all remains undiscovered. The outbreak at present under discussion is one of the few in which a tangible ætiological factor, namely vibration, has presented. It therefore becomes increasingly important to record the exact extent of the vascular disorder of function, for the distribution may vary in other occupations in which a different quality of vibration is encountered.

There was no example, in this series, of vascular disturbances involving the toes or feet. In the hands the colour changes were invariably distributed centrifugally. It was usual for the earliest attacks to involve the tips of the fingers only : if the disease then progressed, the spread was centripetal, but progressive "deterioration" in this respect was by no means the rule. Blanching of the whole length of a finger was sometimes seen from the first attack onwards.

In some cases precisely the same areas of the hands were affected at every attack : in others a mild attack would affect only the tips, but a more serious one usually involved a much greater area. It is not possible to show whether this variability is due to arterial spasm changing in site according to the degree of chilling, or whether it is due to varying degrees of occlusion of an artery by spasm at some fixed point which is proximal to the site of the blanching itself.

The patients always described the extent of the colour changes by reference to the various joints of the fingers. This has suggested a shorthand system of notation which proves of considerable practical value. For the purpose the digits are numbered 1 to 5 , from the thumb to the smallest finger. One stroke after the number then indicates colour changes extending from the tip to the distal interphalangeal joint; two strokes indicates from tip to proximal interphalangeal joint, and three strokes (e.g. $\left.5^{\prime \prime \prime}\right)$ the whole finger to the metacarpophalangeal joint. The unit is thus the length of one phalanx. According to this notation a lesion in the left hand which involved the distal phalanx of the thumb and the whole length of the middle and ring fingers would be expressed as follows :

$$
\text { Left .. .. } 1^{\prime} 3^{\prime \prime} 4 \% \text {, }
$$

while total involvement of all digits in the right hand would be :

$$
\text { Right .. .. } 1^{\prime \prime} 2^{\prime \prime \prime} 3^{\prime \prime \prime} 4^{\prime \prime \prime} 5^{\prime \prime \prime}
$$

In some accounts of Raynaud's phenomenon it has been suggested that the thumb is not involved. Initially nine workers, all men, were found to have involvement of one thumb, while two others had both thumbs involved. Two and a half years later the number had increased to forty-eight, and the occurrence was no longer confined to men. Furthermore, amongst these forty-eight were now twenty with bilateral thumb involvement. This total of forty-eight cases shows that in 17.3 per cent. of the whole series of workers the thumb was involved. 
TABLE 3

PROPORTION OF CASES IN WHICH THE VARIOUS FINGERS WERE INVOLVED AT THE first observed attack OF BLANCHING

\begin{tabular}{|c|c|c|c|c|c|c|c|c|c|c|}
\hline \multirow[b]{2}{*}{ Digit affected } & \multicolumn{5}{|c|}{ Men $($ Total $=163)$} & \multicolumn{5}{|c|}{ Women $($ Total $=21)$} \\
\hline & $\begin{array}{c}\text { Thumb } \\
(\%)\end{array}$ & $\underset{(\%)}{\text { In ex }}$ & $\begin{array}{c}\text { Middle } \\
(\%)\end{array}$ & $\underset{(\%)}{\operatorname{Ring}}$ & $\begin{array}{c}\text { Little } \\
(\%)\end{array}$ & $\underset{(\%)}{\text { Thumb }}$ & $\begin{array}{c}\text { Index } \\
(\%)\end{array}$ & $\begin{array}{c}\text { Middle } \\
(\%)\end{array}$ & $\underset{(\%)}{\text { Ring }}$ & $\begin{array}{c}\text { Little } \\
(\%)\end{array}$ \\
\hline Contralateral hand & 0.6 & $26 \cdot 4$ & $54 \cdot 6$ & $57 \cdot 0$ & $31 \cdot 3$ & Nil & 14 & 24 & 52 & 19 \\
\hline Ipsilateral hand .. & Nil & $6 \cdot 7$ & $7 \cdot 4$ & $6 \cdot 7$ & 4.9 & Nil & Nil & 5 & 14 & Nil \\
\hline
\end{tabular}

Each subject was asked to recall the first attack he or she had experienced. No one had difficulty in indicating the extent of the disorder on that occasion, though in some cases it had occurred four years before. A better indication could scarcely be given of the concern with which a working man regards the first sign of "deadness" in his fingers. The natural handedness of workers has already been shown to be of significance. It is convenient to use the same criterion of " handedness " when considering which of the various fingers were affected at the first observed attack of blanching. This has been done in Table 3, in the cases of the 163 men and twenty-one women found to be affected. In most of them more than one digit was involved.

Most of the men and women, therefore, saw the first evidence of abnormality in the ring and middle fingers. This could mean that these fingers were subjected to more serious trauma than the others, or that the arterial branches supplying them were unusually sensitive to a general vascular disturbance, whatever it might be, or to the precipitating action of cold.
The distribution of lesions at the time of the first interviews in March, 1945, already demonstrated an increase in the extent of the involvement, as Table 4 shows. It was found to be very similar for males and females, so the figures of the two have been combined. The Table therefore concerns a total of 184 cases, and the proportions are expressed as percentages of that number.

The general trend of the figures in this Table agrees with that in the last. The rate of increase of the lesions cannot be computed from them, however, for Table 4 relates to one definite date, whereas Table 3 is drawn up irrespective of dates, because it refers to the first experience of blanching in individual cases. Nevertheless, Table 4 does show that, by March 1945, 89 per cent. of the affected subjects had involvement of the tip of the ring finger in the contralateral hand (which in most cases was the left): over half had involvement of the whole of that finger. The incidence was much less in the right hand, but relatively it was heaviest in the middle and ring fingers, as before.

As far as individual sufferers were concerned, many different combinations of affected fingers were

TABLE 4

PROPORTION OF CASES IN WHICH THE VARIOUS UNITS OF THE FINGERS WERE INVOLVED BY THE TIME OF THE INTERVIEW IN MARCH 1945

\begin{tabular}{|c|c|c|c|c|c|c|}
\hline & Digit & Thumb (\%) & Index (\%) & Middle (\%) & Ring (\%) & Little (\%) \\
\hline \multirow{3}{*}{$\begin{array}{l}\text { Contralateral } \\
\text { hand }\end{array}$} & $\begin{array}{ccc}\text { Tip to distal interphalangeal } \\
\text { joint } & \ldots & \ldots\end{array}$ & - & $57 \cdot 0$ & $87 \cdot 4$ & $89 \cdot 0$ & $70 \cdot 7$ \\
\hline & $\begin{array}{cc}\text { Tip to proximal interpha- } \\
\text { langeal joint }\end{array}$ & , 6.0 & $47 \cdot 6$ & $75 \cdot 0$ & $78 \cdot 8$ & $60 \cdot 8$ \\
\hline & $\begin{array}{c}\text { Tip to metacarpo-phalan- } \\
\text { geal joint }\end{array}$ & 0.5 & $27 \cdot 7$ & $43 \cdot 9$ & $52 \cdot 1$ & $42 \cdot 3$ \\
\hline \multirow{3}{*}{$\begin{array}{l}\text { Ipsilateral } \\
\text { hand }\end{array}$} & $\begin{array}{c}\text { Tip to distal interphalangeal } \\
\text { joint } \quad \ldots\end{array}$ & - & $22 \cdot 2$ & $25 \cdot 5$ & $27 \cdot 7$ & $17 \cdot 9$ \\
\hline & $\begin{array}{cc}\text { Tip to proximal interpha- } \\
\text { langeal joint }\end{array}$ & $2 \cdot 2$ & $17 \cdot 9$ & $16 \cdot 8$ & $22 \cdot 3$ & $14 \cdot 1$ \\
\hline & $\begin{array}{c}\text { Tip to metacarpo-phalan- } \\
\text { geal joint }\end{array}$ & 0.5 & $6 \cdot 0$ & $7 \cdot 1$ & $8 \cdot 7$ & $7 \cdot 6$ \\
\hline
\end{tabular}


found in the present series, but never once were thumb and smallest finger affected together if those between them were normal. Often adjacent fingers were involved, and then the middle one of a group was frequently worse affected than those outside as, for example, in Case 242 :

$$
\text { Left .. . . 2 } 2^{\prime \prime} \quad 3^{\prime \prime \prime} 4^{\prime \prime}
$$

Sometimes a single finger escaped in spite of involvement of those on each side, as in Case 233 :

$$
\text { Left .. . } 2^{\prime \prime \prime} 4^{\prime \prime \prime}
$$

but the commonest distribution was involvement of several fingers all to the same degree :

Case 47 : Right .. .. 2' $2^{\prime} 4^{\prime}$

Case 245: Left $\ldots . . .33^{\prime \prime} 4^{\prime \prime} 5^{\prime \prime}$

Case 72: Left .. $\quad . \quad 2^{\prime \prime \prime} 3^{\prime \prime \prime} 4^{\prime \prime \prime} 5^{\prime \prime \prime}$

Involvement of the Palm.-Vascular disturbances were not only confined to the fingers and thumb. Five men, all of whom had been engaged in the heaviest kind of scurfing work, had had attacks which extended from the finger tips into the palm of the hand. The distributions in these cases were as follows :

Case 27.-Attacks in the left hand involved the thumb, all the fingers, and the palm to a horizontal line from the root of the thumb, that is, $1 \frac{1}{2}$ inches proximal to the web of the fingers.

Case 28.-The middle, ring, and index fingers of the left hand were involved, and also the palm to a line extending from the root of the middle finger diagonally across to a point on the ulnar border of the hand two inches proximal to the root of the little finger. This claim was amply confirmed when the man's hands were immersed in cold water.

Case 147.- The distribution was the same as in Case 27 except that the thumb was unaffected.

Case 228.-It was said that blanching. took place in the middle, ring, and little fingers of the left hand and extended proximally "as far as the wrist," though the thumb, index finger, and radial half of the palm were, seemingly, unaffected. This claim could not be fully substantiated by the immersion test but, as will be shown, this fact does not discredit it entirely.

Case 231.-The distribution was exactly similar to that in Case 28.

This evidence suggests strongly that temporary occlusion can take place in the common digital and metacarpal arteries at least as far proximally as the points where they arise from the palmar arches ; it also suggests that both these sets of arteries are affected simultaneously.

Cyanosis.-Those who had noticed colour changes usually spoke first of " whiteness" or "waxiness" of the fingers. This whiteness would eventually give place to red and white mottling, or to the uniform bright red colour which is evidence of reactive hyperæmia. The last stage is often accompanied by unpleasant sensations of " prickling " or " tingling," and sometimes even of acute pain. Indeed, such discomfort usually heralds the return of normal circulation. Many of those who were affected described in addition a succession of colour changes from "whiteness" to "waxiness," to " blue," " grey-blue," "blue-black," or " black," before the return to redness and normality after a variable delay. Others used the words "dusky," "leaden-blue colour," "violet," or " purple." Descriptions of this kind obviously imply a stage of cyanosis of the fingers, and this could be seen in many cases during the immersion test.

TABLE 5

INTERVAL ELAPSING BETWEEN THE ONSET OF BLANCHING AND THAT OF CYANOSIS IN A SERIES OF MALES, BY SIXMONTHLY PERIODS

\begin{tabular}{c|c|c|c|c|c}
\hline & \multicolumn{3}{|c|}{$\begin{array}{c}\text { Interval } \\
\text { (months) }\end{array}$} & $\begin{array}{c}\text { Total } \\
\text { subjects }\end{array}$ \\
\hline \begin{tabular}{c|c|c|c|c|} 
(simul- \\
taneous)
\end{tabular} & $1-6$ & $7-12$ & $13-18$ & $19-24$ & \\
\hline 18 & 44 & 18 & 11 & 6 & 97 \\
\hline
\end{tabular}

Hunter, McLaughlin, and Perry (1945) observed that cyanosis was uncommon in cases of Raynaud's phenomenon brought about by the use of pneumatic hammers. Nevertheless cyanosis was far from rare in the present cases, for 111 (68 per cent.) of the affected men and twelve (57 per cent.) of the women described it in a way which left no doubt of the matter: The onset of cyanosis in relation to that of blanching in the case of the ninety-seven men who could give precise dates repays study. Eighteen of them said that cyanosis had appeared at the very first attack of vascular disturbances. "Never, on the other hand, had it been delayed longer than two years after the first attack of simple blanching. The distribution is shown in Table 5.

The mean interval was 6.4 months. It may be objected that cyanosis could have appeared in many more of the men who already experienced attacks of blanching, had they been longer at the work. Table 6 suggests that this may indeed be the case. It shows the time which had elapsed between the onset of symptoms and the date of the enquiry (March, 1945) for the fifty-two men (163 minus 111) who talked of blanching but had not noticed cyanosis.

Since twenty-eight of these men had only experienced attacks of blanching for six months or less, it is to be expected that some at least of them would exhibit cyanosis if watched for a further eighteen months. 
TABLE 6

LENGTH OF PERIOD OF OBSERVATION FROM THE FIRST ONSET OF BLANCHING IN THE CASE OF MEN not EXHIBITING CYANOSIS

\begin{tabular}{c|c|c|c|c|c}
\hline \multicolumn{4}{c|}{$\begin{array}{c}\text { Period of Observation } \\
\text { (months) }\end{array}$} & $\begin{array}{c}\text { Total } \\
\text { subjects }\end{array}$ \\
\hline $1-6$ & $7-12$ & $13-18$ & $19-24$ & $25-30$ & \\
\hline 28 & 12 & 6 & 4 & 2 & 52 \\
\hline
\end{tabular}

The tendency towards cyanosis might perhaps be related to age of the subject. This could be tested by observing the incidence of cyanosis in two groups of men in separate decades, provided that they had had comparable exposure to risk. Table 2 on page 150 (which is, however, drawn up to include women as well as men) suggests that the decades 30 to 39 and 50 to 59 years might be sufficiently comparable. Table 7 shows that two closely comparable groups do result if those males in these two decades who have done more than six months' scurfing work are considered. It is, "therefore, permissible to compare the incidence of cyanosis in the two age groups.

This suggests that there is some tendency, provided that exposures to risk are comparable, for the younger men to exhibit cyanosis more often than the older.

It has already been suggested that cyanosis is the more to be expected the longer a man suffers attacks of vascular disturbances ; likewise, there is already good evidence that the anatomical extent of the lesions increases the longer a man continues in this work. A tendency to cyanosis should, therefore, go hand in hand with the clinical severity of the lesion if the latter is measured in terms of anatomical extent. From many points of view it is useful to measure "severity" thus, because its assessment

TABLE 7

SIMILARITY OF TWO AGE-GROUPS OF MEN IN RESPECT OF LENGTH OF EXPOSURE TO VIBRATION, AND INCIDENCE OF

\begin{tabular}{c|c|c|c|c}
\multicolumn{3}{c|}{ CYANOSIS IN THE TWO } \\
\hline $\begin{array}{c}\text { Exposure to } \\
\text { vibration } \\
\text { (months) }\end{array}$ & Aged 30 to 39 & Aged 50 to 59 \\
\cline { 2 - 4 } & Total & Cyanosis & Total & Cyanosis \\
\hline $7-12$ & 5 & 4 & 5 & 0 \\
$13-18$ & 6 & 2 & 4 & 2 \\
$19-24$ & 7 & 7 & 5 & 3 \\
$25-30$ & 3 & 2 & 5 & 4 \\
$31-36$ & 5 & 5 & 3 & 1 \\
$37-42$ & 5 & 3 & 7 & 5 \\
43 and over & 0 & 0 & 1 & 1 \\
\hline Total & 31 & 23 & 30 & 16 \\
\hline Cyanosis & 74 per cent. & 53 per cent. \\
\hline
\end{tabular}

depends only upon an accurate anamnesis-which is not difficult to obtain in this disease : records, moreover, are simple to keep, and comparisons easy to draw. It is certainly the measurement which seems most logical to the patient.

To make it possible to compare proclivity to cyanosis with severity of lesion, the index of severity arbitrarily chosen here is the extent of vascular disturbances in the worst affected of the hands. As before, this can be expressed numerically as the aggregate number of "units" or joints of finger involved. The resulting figure will be called the " index of severity." Thus, complete involvement of all fingers and thumb calls for an index of severity of 14 . It would have been equally feasible to take as the index the aggregate of all the " units" involved in both hands, with a maximum of 28 .

TABLE 8

TO SHOW THE PERCENTAGE OF CASES EXHIBITING CYANOSIS BY GROUPS ACCORDING TO SEVERITY OF LESION

\begin{tabular}{|c|c|c|c|}
\hline $\begin{array}{l}\text { Index of } \\
\text { severity } \\
\text { (units) }\end{array}$ & $\begin{array}{c}\text { No. of } \\
\text { cases }\end{array}$ & $\begin{array}{l}\text { Cases } \\
\text { with } \\
\text { cyanosis }\end{array}$ & $\begin{array}{c}\text { Percentage } \\
\text { with } \\
\text { cyanosis }\end{array}$ \\
\hline $\begin{array}{rlr}1 \text { and } & 2 \\
3 & , & 4 \\
5 & , & 6 \\
7 & , & 8 \\
9 & , & 10 \\
11 & , & 12 \\
13 & , & 14\end{array}$ & $\begin{array}{r}7 \\
20 \\
39 \\
23 \\
39 \\
31 \\
4\end{array}$ & $\begin{array}{r}1 \\
7 \\
23 \\
17 \\
30 \\
29 \\
4\end{array}$ & $\begin{array}{r}14 \\
32 \\
59 \\
74 \\
79 \\
94 \\
100\end{array}$ \\
\hline Totals & 163 & 111 & 68 \\
\hline
\end{tabular}

However, a lesion of 14 units in one hand appears, to the patient and other observers alike, to be of more consequence than one of 14 units divided between the two hands.

Cyanosis and severity are compared in Table 8, which shows convincingly that the tendency to exhibit cyanosis bears a direct relationship to the severity of the disease expressed in terms of its anatomical extent.

Immersion.Test.-The procedure adopted for this test has already been briefly described. It cannot be compared in accuracy with the usual thermometric laboratory tests of the reaction of vessels to cold. Nevertheless it was simple to use and adaptable to the cramped conditions of a factory first-aid post, provided that running water was available. One advantage was that it took only fifteen minutes to perform, for speed is a matter of importance in dealing with a group of men and women who are anxious to lose no more working time than is necessary. The test allowed the observer some chance of reproducing artificially the vascular disturbances about which he was being 
told. It was open to the objection that the experimental conditions could seldom be kept constant. A deep sink provided with running water from the mains, the temperature of which varied no more than $1^{\circ} \mathrm{C}$. from day to day, ensured uniformity in the local application of cold. But the temperature of the room varied considerably throughout the day, and the outside air through which the subjects walked for varying distances to come for interviews was of even less uniform temperature. Some subjects protested that their test would show nothing abnormal because they were thoroughly warm from hurrying to the examination; and in several such cases it was negative. Others said that no signs would appear on immersion because their hands had only just recovered from an attack of blanching. Such an occurrence would suggest that a refractory interval exists after the spasm in an artery has been relieved. Negative tests in two severe cases, which otherwise might have been expected to produce blanching easily on immersion, lent support to this idea. More accurate tests under laboratory conditions are needed to establish it.

In order to evaluate the immersion test it is, of course, necessary to accept without question the testimony of patients regarding the presence or absence of attacks of Raynaud's phenomenon. The assessment cannot be entirely objective.

A positive result was recorded in all cases where there was blanching or cyanosis of orthodox distribution, with a distinct line of demarcation between normal and abnormal skin colour. Seven out of the twenty-one women who said they were affected showed a positive immersion test, but it is not profitable to analyse this small number further. Of the 163 men who considered themselves affected, 111 (68 per cent.) had a positive test. These were not the same 111 individuals who gave a history of cyanosis (see p. 153): the exact similarity of the number is fortuitous. The area of the disturbance shown in the test never appeared as extensive as that described in the history. Cyanosis during the test was actually observed in sixty-three out of this group of 111. On the basis of the history they gave, eighty-eight out of the 111 could have exhibited cyanosis, so in this respect the test reached 72 per cent. of expectation.

A positive result to the test was more often obtained in the severe cases than the mild. This is well shown in Table 9, which compared the percentage of positive immersion tests in groups arranged according to the "index of severity," as previously defined, based as before on the subjects' histories.

This Table also illustrates the difficulty of interpreting the test when lesions of only slight or moder- ate degree of severity are being claimed. A positive test supports a claim of vascular disturbance incontrovertibly, but a negative one will not prove that the claim is false. Great care must clearly be exercised in using test as additional evidence in a case which has become the subject of litigation. In less controversial circumstances the immersion test appears to be useful. A diagnostic aid of such simplicity as this should not perhaps be lightly condemned on grounds of the inconsistency of its results, since its limitations can be defined, on the evidence of Table 9. Probably the full extent of the lesion claimed will not be reproducible under consulting-room conditions, so a test should be called positive on the mere presence of colour changes, not on their extent.

TABLE 9

INCIDENCE OF POSITIVE IMMERSION TESTS COMPARED WITH THE " INDEX OF SEVERITY"

\begin{tabular}{|c|c|c|c|}
\hline $\begin{array}{l}\text { Index } \\
\text { of } \\
\text { severity }\end{array}$ & $\begin{array}{l}\text { No. } \\
\text { of } \\
\text { cases }\end{array}$ & $\begin{array}{c}\text { Cases with } \\
\text { positive } \\
\text { immersion test }\end{array}$ & $\begin{array}{l}\text { Percentage - } \\
\text { with positive } \\
\text { test }\end{array}$ \\
\hline $\begin{array}{rrr}1 \text { and } & 2 \\
3 & , & 4 \\
5 & , & 6 \\
7 & ,, & 8 \\
9 & , y & 10 \\
11 & , & 12 \\
13 & ,, & 14\end{array}$ & $\begin{array}{r}7 \\
20 \\
39 \\
23 \\
-39 \\
31 \\
4\end{array}$ & $\begin{array}{r}3 \\
9 \\
26 \\
16 \\
27 \\
26 \\
4\end{array}$ & $\begin{array}{r}43 \\
45 \\
67 \\
70 \\
69 \\
84 \\
100\end{array}$ \\
\hline Total & 163 & 111 & 68 \\
\hline
\end{tabular}

Effect of Variations in Type of Work on Incidence of Disease.-An attempt must be made to correlate the incidence and severity of the lesions with the various types of work which were being done in this factory with rotary hand tools.

Certain of the women had been called upon to use only the smallest cutting "heads." Though this should have been in theory an important group to study, it was too small to enable useful conclusions to be drawn. A second group of workers had changed too often from one type of head to another.

A third group consisted of men who had been employed all the time in polishing steel crankshafts either with " buffs " made of felt dressed with emery powder, or with small silicon carbide stones. Women did not do such work. The twenty-four men concerned were mostly between the ages of 40 and 53. Only ten of them were affected, and the lesions were of all degrees of severity. The incidence of Raynaud's phenomenon (42 per cent.) amongst them is considerably below the incidence $(69.9$ per cent.) for the whole male series. The period during which they were exposed to risk before the onset of 
symptoms varied from twelve to forty-eight months, with a mean of 23.5 months. This is the same figure as for the male series as a whole. It seems unlikely that most of the fourteen unaffected men in this group had escaped trouble simply because they had not been at risk long enough, for their average exposure to vibration was already $27 \cdot 1$ months. The available evidence suggests that the task of polishing crankshafts is somewhat less likely to produce Raynaud's phenomenon than the other operations, but that the nature of the lesion is not appreciably different when it'does appear.

The last which will be considered is a group of eighty-nine men who had spent the greater part of their time scurfing with the largest of the cutters. This was without doubt the most arduous of the scurfing work. These men were of all ages, and

TABLE 10

DISTRIBUTION OF THE SEVERITY OF LESIONS IN THE WHOLE SERIES COMPARED WITH THAT IN A GROUP OF MEN SOLELY EMPLOYED ON LARGE CUTTING HEADS

\begin{tabular}{|c|c|c|}
\hline $\begin{array}{l}\text { Index of } \\
\text { severity }\end{array}$ & $\begin{array}{l}\text { Whole series } \\
\text { (expressed as a } \\
\text { percentage of a } \\
\text { total of 163) }\end{array}$ & $\begin{array}{l}\text { Series of men } \\
\text { using large } \\
\text { cutters only } \\
\text { (expressed as a } \\
\text { percentage of a } \\
\text { total of } 80 \text { ) }\end{array}$ \\
\hline \multirow[t]{2}{*}{$\begin{array}{rrr}1 & \text { and } & 2 \\
3 & , & 4 \\
5 & , & 6 \\
7 & \text { ", } & 8 \\
9 & , & 10 \\
11 & , & 12 \\
13 & , & 14\end{array}$} & $\begin{array}{r}4 \cdot 3 \\
12 \cdot 3 \\
23 \cdot 9 \\
14 \cdot 1 \\
23 \cdot 9 \\
19 \cdot 0 \\
2 \cdot 5\end{array}$ & $\begin{array}{r}3 \cdot 8 \\
8 \cdot 8 \\
21 \cdot 2 \\
15 \cdot 0 \\
25 \cdot 0 \\
22 \cdot 5 \\
3 \cdot 7\end{array}$ \\
\hline & $100 \cdot 0$ & $100 \cdot 0$ \\
\hline
\end{tabular}

eighty out of eighty-nine ( 90 per cent.) were affected. Furthermore, sixty-five of these eighty men $(81 \mathrm{per}$ cent.) had observed cyanosis during their attacks. The incidence of blanching and of cyanosis is thus higher than in the whole group, where the figures were 69.9 per cent. and 68 per cent. respectively. Once again the mean duration of exposure to risk before observing symptoms, namely. 23.6 months, was scarcely different from the mean for the entire series. The severity of the lesions in these eighty men can be compared with that for all the males in the series, as in Table 10, using the index of severity already described.

The distribution of cases by severity agrees closely in the whole series and in the part.

There is thus evidence to suggest that working with large cutters makes for a higher total incidence of vascular disorders, but that these do not arise any more rapidly, nor are they appreciably more extensive than in the series as a whole.
Other Clinical Findings. - There were few abnormalities apart from those in the peripheral vascular system, but it is of importance to record the negative findings briefly.

There was no evidence of local skin lesions on the fingers or hands, none of trophic changes, and none of sclerodactyly. There was no sign of the permanent occlusion of any vessel, large or small, and no suggestion of impending gangrene. The radial pulses were palpable in all cases. Benign hypertension was discovered in twenty-seven cases, but it was never severe : a raised blood pressure did not seem sufficient abnormality by itself to warrant the exclusion of a case from the series. Raynaud's phenomenon caused simply by arteriosclerotic changes is a rare enough happening.

Callosities were much in evidence on the hands, but they were not distributed in such a way as to become a definite stigma of this occupation.

One man had symptoms and signs to suggest osteoarthritis of the shoulder-joints, but evidence of arthritis .was otherwise lacking. There was no wasting of the small muscles of the hands. The neurological examination was always negative, except for a relative hypalgesia at the finger tips when these were cold: the hypalgesia did not seem to be confined to the fingers which had been reported abnormal. There was nothing to suggest that any patient was suffering from a cervical rib, but radiographs of the neck were not taken. The incidence of Raynaud's phenomenon was very high in this series, and it is scarcely likely that a significant number of cases could have been due to undetected cervical ribs. Blood counts, Wassermann reactions, and radiographs of the wrists or carpal bones were not attempted.

\section{THE COURSE AND INCIDENCE OF THE DISEASE : LATER FINDINGS}

An interval had now to pass before the progress or sequelæ of the disease in individual cases could be studied. In mid-summer 1947 it became known that the factory had closed down. The workers had dispersed to their normal peacetime occupations, and many had moved to other districts. A second personal interview with each was already out of the question. The longer the delay, the greater would this dispersion have been, so in September, 1947, two and a half years after the first examination, a circular letter and questionnaire were sent to all the workers concerned. A - second physical examination was precluded.

The aim of the questionnaire was to decide, as far as is possible from any such enquiry by post, the following questions :

(a) What proportion of those who had previously escaped attacks of Raynaud's phenomenon had since become affected.

(b) Whether it is possible for the condition to appear after a worker had.given up the work. (The fact that the works had shut down would make this easier to determine.)

(c) Whether the condition in those already affected was improving, remaining stationary, or deteriorating : 
also, whether any relationship existed between the course of the disease and the cessation of scurfing work.

(d) Whether the anatomical extent of the disorder had increased in any cases, and whether any fresh symptoms had arisen.

(e) Whether any workers considered themselves handicapped by their condition, "and if so, for what reasons. Any disability in respect of their new occupations was to receive particular attention.

Separate questionnaires were devised for those who had already been affected and for those who had hot been subject to attacks of vascular disorders by the time of the first examination. Information was requested concerning the date of ceasing scurfing work, the nature of the subsequent employment, and the onset or cessation of attacks. The present anatomical extent of the lesion during a full attack was to be shaded in on the outline drawing of the hands which was provided. Further questions related to the events which brought on attacks and the progression of colour changes to be seen, while others sought a personal estimate of the improvement or deterioration, and the grounds for the opinion offered. Finally, each worker was asked whether attacks came on while the work was going on, whether they were causing hindrance and, if so, in what particular way. Space was left at the end for free personal comment. It was by then autumn, and a word of warning was added explaining that attacks would probably have been few in summer. Everyone was, therefore, asked to recall the previous winter's experiences before answering.

If the second enquiry had also been conducted in the month of March, it would have given results more comparable with those obtained previously. In view of the difference in season, the answers given in the 1947 survey make possible a conservative estimate of the later extent of the disorder and the disability it was causing to individual workmen.

Of the original 278 men and women making up the whole series, 189 (67.9 per cent.) completed and returned the questionnaire. Of the rest, three men were reported to have died of other diseases, while in thirty-one cases the papers were returned uncompleted because the addressee had moved and his whereabouts was unknown. No reply was obtained from the remaining fifty-five despite a second letter asking for co-operation. It is certain that some of these defaulters had filed claims for compensation and were anxious not to do anything which might prejudice their chances.

It is convenient to consider the findings separately for those with established vascular disorders at the first examination, and those without.

Group A : Those who were Previously Free from Vascular Disorders. - Of this group, sixty-one out of a possible ninety-four completed the questionnaire: but in three of the cases the information offered was too inexact to warrant inclusion. Less than half (twenty-seven) of them were still free from symptoms, and twelve of these were women.

These twenty-seven men and women who still gave a negative history had worked at scurfing for periods of between eight and fifty-six months, the mean being 32.4 months. Eleven of the fifteen males had either spent their time polishing crankshafts with an emery-dressed buff or had done light scurfing with only the smaller cutters: this indirectly suggests that work with the larger cutters is the more harmful, as already discussed.

Because of the closing of the factory, these twenty-seven symptom-free subjects had already given up this work for periods varying between nineteen and twenty-four months without the slightest abnormality having appeared.

The remaining thirty-one people in group A had developed symptoms since the original interview. It is unlikely that, without exception, all those who failed to return their questionnaires had also become affected in this interval; it is equally unlikely that they were all still free from symptoms. In the former event those who remained persistently symptom-free could have constituted only 9.7 per cent. of the original series of 278 ; in the latter event, they could have constituted 22.7 per cent. In September, 1947, therefore, the true proportion of positive cases must have reached between $77 \cdot 3$ per cent. and 90.3 per cent. of the original total.

The individual histories of the thirty-one fresh cases were examined: attacks were nearly all attributed to cold, but five men specifically blamed certain actions, such as carrying buckets, which called for strong gripping by the affected hand. One man was sure that extremes of both heat and cold started off his attacks. The claims of these people to have suffered disability will be discussed below.

Group A cannot be left without reference to the fact that two of its members developed their first symptom in the very month in which they had stopped scurfing work and left the factory. A further eleven first saw the disturbances appear some time after they too had stopped. In two cases it was one month later, in two it was two months, and in four cases it was three months later. The remainder were affected seven, twelve, and sixteen months afterwards respectively. Therefore, it is quite certain that ceasing to work with vibrating tools does not guarantee freedom from vascular disorders in the ensuing months. At present no estimate of the maximum latent period can be made. There is evidence from one case that 
symptoms can develop not in the first cold spell, but at an even later date after such work has been abandoned.

Group B : Those who were Already Suffering from Vascular Disorders at the First Examination.From a possible total of 184,128 replies $(69.6$ per cent.) to the questionnaire were received.

All but three of these patients were still subject to attacks of Raynaud's phenomenon, and of these, two had still been subject to them during the coldest part of the previous winter and might be expected, therefore, to have further trouble in the winter which was to come. Only one subject (Case 55) in the whole investigation could claim a complete cure after having watched events through a severe winter.

Each man and woman had been encouraged to make a personal assessment of the progress of the disorder. In 64 cases (50 per cent.) the opinion was that the condition was stationary. Eight subjects (6.3 per cent.) were unable to give a definite answer : apart from Case 55, a further nine (7.0 per cent.) felt that there had been some improvement, though symptoms still occurred from time to time.

The remaining forty-six (36 per cent.) claimed that their condition had deteriorated in the $2 \frac{1}{2}$-years interval, whether judged by the number or the duration of attacks or by the number of the fingers attacked each time. All these forty-six had stopped working with vibrating tools for from seven to thirty months, and had been hoping for some improvement as a result.

A general survey of these case histories left no doubt that it was common for the condition to have remained unchanged, that deterioration, too, was common, but that improvement in the interim was unusual, and a cure exceptional. Nevertheless, serious sequelæ such as trophic lesions, scleroderma, or gangrene were not reported. The profusion of personal comments offered makes it likely that such things would have been mentioned if they had occurred.

In short, on this and other evidence above, Raynaud's phenomenon of occupational origin shows a greater tendency to progress than to disappear, at least in the early years after exposure to risk. This is a fact which calls for early recognition.

Anatomical Distribution at the Second Enquiry.The distribution reported in September, 1947, was compared with that of March, 1945. Of the subjects who had had both hands affected there were now five in whom the right hand had become normal. In contrast, there were thirty who had started with a unilateral lesion (usually on the left) and had had the second hand affected during the follow-up period, although in some cases they had already given up the work before this happened. Involvement of the second hand is, of course, a particularly noticeable event in the natural history of the disease, so that when reported it can be accepted as good evidence of an extension of the lesion.

There were a number of small changes in the anatomical distribution of blanching. In thirtythree cases, that is, in 25.8 per cent., of the follow-up series, one finger had improved whilst another had become involved. This is probably a greater number than could be explained by the personal inaccuracies of patients when observing and reporting their symptoms, particularly as in such cases the broad distribution in the rest of the hand remained the same.

The precise area involved was again expressed numerically in units of one phalanx and compared with the involvement on the earlier occasion. The mean increase or decrease was derived for the whole follow-up series by using the algebraic sum, to allow for individual cases in which there was improvement in one finger and deterioration in others. The mean figure for the change in all these 128 cases was $+4 \cdot 3$ units; that is to say, on the average each patient was now having $4 \cdot 3$ more phalanges or nearly $1 \frac{1}{2}$ more fingers affected in each attack. This is direct evidence of the tendency of the disease to progress. The greatest single progression was one of twenty-five units; not only had the distribution increased in the left hand of the man concerned, but all the fingers and the thumb of his right hand had now become involved, although this hand had been normal in 1945 .

Analysing further, there were twenty-two in whom the records showed that there had been a real diminution in the area affected; that is to say, in these cases there was " improvement." Only nine people, it will be recalled, claimed improvement from their own general observations, so an exact clinical record of the area involved at each stage is of value. The greatest single improvement was only of 7 units, and in only the one case already discussed (Case 55) was recovery complete. In six cases no change at all was observed in the $2 \frac{1}{2}$-years interval. In the remaining hundred cases the extent of the lesion had increased.

Precipitating Factors.-Cold was still considered the most important factor in precipitating attacks. There were some patients who suggested that they had only to grasp -objects firmly for blanching to appear. This was a feature of the history which had seldom been observed before. Some had noticed that chilling of the body as a whole was of 
as much significance in producing attacks as the coldness of the extremities themselves. Two men had experienced Raynaud's phenomenon after hot baths as well as after washing in cold water. This is a remarkable statement for them to have made, but they had recognized it as such and had enlarged upon it. At first sight it would appear that the trunk and extremities should be warmer after a hot bath than at any other time, but it is possible that in such circumstances the high rate of cooling, rather than the exact temperature of the body or limb at the time, leads to arterial spasm.

One man now complained that his attacks were precipitated by excitement. This is the only history of its kind in this series, but it has been observed before in other cases of Raynaud's phenomenon of quite different ætiology.

Frequency of Attacks.-It is difficult for most patients to give an estimate of the frequency of attacks, for they are seldom in the habit of recording them in a notebook. Many men were able to give broad estimates, and it was almost the rule for attacks to have occurred daily, or even many times a day, in the winter months. Ninety-three members of the follow-up series (72 per cent.), had had variable attacks during the summer also. A few had had daily attacks at all seasons, whatever the weather.

The comparative rarity of attacks during working hours has already been remarked upon in a previous section, where it was attributed to the warmth generated by the scurfing tool and the excellent conditions prevailing in the workshops. Once having left these conditions, however, the men began to complain more often of attacks while at their work. In 1945, 19.6 per cent. of those with vascular disfurbances had made this complaint; in 1947 the figure was 79 per cent. of all those in the follow-up series who fall into Group B. As Group B is derived from the same population of workers, it is permissible to compare these proportions, although the figure of 79 per cent. would be too large if those who had this complaint should happen to have been more anxious to return the questionnaire than the rest.

\section{Disability.}

The well-recognized disabilities of occupational origin may be easy to assess, such as the loss of an eye or limb in an accident at work, or they may be difficult, as in the case of silicosis. But commonly they are long-standing or permanent disabilities which vary little from day to day. The victim is often unable or forbidden to continue at the work which caused his disablement.
With vascular disturbances which produce Raynaud's phenomenon it is a different matter. The disease does not necessarily prevent a man from continuing in the same work-as in the present series of cases-even though he may be advised against it. When the disability does appear, it is transient, being present one moment and relieved the next ; also, it is dependent upon external factors such as season, climate, and room temperature.

In 1945 few of the workers concerned in this outbreak talked of disability. It is true that they expressed anxiety for the future besides annoyance that their fingers should go "dead" on cold mornings. But of disability, in the sense of loss of working time or efficiency, there was none; for no one was prevented from coming to work in the morning simply because of an attack of blanching of the fingers, and no one lost a full working day, much less several consecutive days, from this cause alone. Many, regardless of symptoms, would have been content to continue at this work indefinitely, but there was no more to be had. Eventually, therefore, the presence or absence of disability in these workpeople came to be determined simply by the nature of the work which they undertook afterwards. This is an unusual state of affairs which calls for further examination.

In the questionnaire of September, 1947, those affected were asked to say whether or not their attacks of Raynaud's phenomenon hindered them in their present work, and to give reasons. There were many answers in the affirmative, but those unsupported by reasons were disregarded. Sixtyfive of them appeared to be supported by sound reasons unemotionally stated : they are given case by case in the Appendix. In some of them hardship is all too apparent, as in the case of a polisher of copper rollers who returned to his own trade only to find himself quite incapable of pursuing it : he was then aged 49 and he was not trained for any other work (Case 101). A postman (Case 45) described how he was obliged to seek relief from his attacks by asking at the houses he visited for warm water in which to wash his hands. One or two people volunteered an estimate of their weekly loss of earnings because of disability. Some had been forced to leave work of their choice for something they liked less.well. Others were unemployed and considered themselves at a disadvantage in a competitive labour market. At least one man feared that he would be dismissed if his employer should see the extent of his disability.

There were a number of textile workers who claimed that their work was being hindered by their attacks, but they recognized that their loss of time or efficiency was usually confined to the mornings, 
because they arrived at work with blanched fingers. The working temperature of the mill, which was high, eventually restored the circulation, and they would have no more attacks that day.

Sixty-three men and women denied being in any way hindered in their new employment. Many of them were working indoors, and some were at pains to explain that they had particularly warm jobs, such as stoking boilers or rivet-heating. Such men will remain free from symptoms only for as long as they are able to keep satisfactory employment of this kind.

A warm job is the solution to the problem of finding full employment for these affected workpeople, but many of the warm jobs are exceptionally arduous, uncongenial, or poorly paid. A worker who found himself restricted narrowly in the choice of an occupation might with some justice consider himself " disabled," whatever else he suffered.

\section{Discussion}

The claim of many of these people to be disabled cannot be disregarded. Nor is it right to ignore the fact that there are many hundreds of riveters, fitters, and grinders in Great Britain who, though affected by the same disorder, make light of their symptoms and continue at work for years. These latter have regular work of their own choice, and need for carrying it out a firm grip without particular delicacy of touch. As the vascular disorder has little effect on their grip, they do not consider themselves disabled. The temper of a group of industrial workers, itself dependent upon their sense of economic stability, may have much to do with their claims to disabilities. Thus, in a different outbreak (Agate, Druett, and Tombleson, 1946) the thirty-two who were affected had regular work, with every prospect of continuing it, and they hardly complained of disability.

The circumstances in the present outbreak were quite different. When first seen in 1945, the workers were already threatened with the loss of their jobs, and they cannot be blamed for being concerned at their symptoms : yet even then they were not claiming to be disabled from working. Later their disability claims reflect the variety of jobs to which they had moved. It is worth noting in how many jobs vascular disturbances are considered a handicap.

Moreover, though this handicap may never mean the loss of full days of work, it could cause in the aggregate several hours of lost time per week, with loss of efficiency, wages, and status.

At the time of the outbreak vascular disorders were not specifically scheduled under the Workmen's Compensation legislation then in force. Legal actions have since been brought against various employers on the plea that the disorder was the result of injuries received in accidents. Thus, in one such case, the verdict was finally given in favour of the workman, since the Court was of the opinion that each vibration caused by a rapidly rotating instrument was, as it were, an infinitesimal blow to the nerves causing an infinitely small damage to their tissues, in the end cutting off the flow of blood needed to keep the hand in a healthy condition. The mere fact that the breakdown did not occur until the cumulative effect of the tiny blows from the vibrations had produced a certain degree of alteration in the nerves, did not affect the character of the cause. It appears likely that any future claims made on the same grounds in the courts would be upheld. But few working men are willing to undertake the considerable financial riskis of an action at law.

Whatever the legal interpretation of the cause of the disorder and the liability or otherwise of employers, the known facts demonstrate that vascular disorders can often be attributed to occupational factors, and to vibration in particular. The present outbreak was discussed in the House of Commons in November, 1945. In the course of replying to a question, the Minister of National Insurance said :*

"I am advised that there is not sufficient evidence that Raynaud's disease is so specific to employment as to justify its inclusion in the Schedule of Industrial Diseases under the Workmen's Compensation Act."

There seems to have been some confusion in the terminology, for if the usual definitions are accepted, Raynaud's disease (sic) is not related to employment, whereas there is the strongest evidence of a specific occupational disease which causes attacks of Raynaud's phenomenon.

At present this disorder is not included in the list of industrial diseases for which industrial injury or disablement benefit can be claimed, as prescribed under the National Insurance (Industrial Injuries) Act 1946. Its inclusion would present peculiar difficulties. A new conception of compensatable disability would have to be admitted, since this disability when present is recurrent, yet it lasts only a few minutes or hours (not days) at a time. Moreover, if the victim tries one kind of work, the handicap may be serious, but if another, it may vanish. It would be logical, though scarcely practicable, to re-assess this disability with every change of occupation. The writer believes that, in spite of the difficulties of including Raynaud's phenomenon of occupational origin with the other prescribed diseases, and in spite of the danger of such action leading to abuses and unnecessary

\footnotetext{
* See Hansard for Nov. 8, 1945.
} 
claims, some consideration should be given to the difficulties under which the genuinely handicapped are labouring.

Three points in particular arise from the clinical study. First, the very high incidence of the disorder amongst the population at risk. Secondly, the frequency with which pallor was observed in attacks some months before cyanosis first appeared. Once cyanosis had appeared it was seen again at nearly every subsequent attack. The third observation is that the arterial spasm, which is usually taken to be the disorder of function, may vary in site from time to time in the same subject ; in some, the involvement of the palm suggests spasm in an artery proximal to the digital vessels. Barker and Hines (1944) published an arteriogram of the hand in a pneumatic tool worker in which occlusion of the ulnar artery at the wrist is clearly shown.

Agate and Druett (1947) recorded the vibration spectra of a number of different tools and concluded that the most harmful vibration lies in the range of 40 to 125 cycles per second, particularly if the amplitudes in that range are of the order of 100 microns or more. The same paper shows that the rotary tool now in question produces appreciable vibration in that very range, whatever the working conditions are.

Elimination of harmful vibration from tools must in the end be the concern of engineers, for absorbent materials and other protective devices are not effective.

\section{Summary}

A fresh outbreak of cases of Raynaud's phenomenon has lately occurred in which the victims were men and women who had the job of polishing metal castings with a rotary tool. The characteristics of this tool and methods of using it are described.

As many as possible of the workers were interviewed and examined, and 278 valid case histories have been analysed. On the first survey 69.9 per cent. of the 233 men and 47 per cent. of the forty-five women were found to be suffering from attacks of Raynaud's phenomenon: these attacks occurred in workers of all ages over 20 , and were precipitated by cold. As a rule a worker's dominant hand was affected less often, later, and less severely than the other, because of the way the tool was held.

The average time taken for a man to develop symptoms was $23 \frac{1}{2}$ months : this was independent of his age. When both hands were involved, as was the case in 43.5 per cent. of the patients, the second one was affected after an average delay of 6.6 months.

A convenient system of notation for recording the anatomical extent of the lesions is described.
The ring and the middle fingers were most affected.

The occurrence of cyanosis during attacks is discussed. It usually appears about six months after the first evidence of blanching. Younger men may be somewhat more prone to cyanosis than older ones. The incidence of cyanosis in various groups is compared with the severity of the lesion, using an arbitrary " index of severity," and a direct relationship between them is shown to exist.

A simple diagnostic aid in the form of a coldwater immersion test is described, and its practical limitations and interpretation are discussed. The likelihood of a positive result to the test is directly related to the extent of the blanching as described by the patients. The effect of variations in the type of work on the incidence of disease is shown. Light polishing of steel components produces a relatively low incidence of lesions, whereas scurfing of duralumin with large toothed cutters causes an exceptionally high incidence.

Two and a half years after the first enquiry a questionnaire was circulated, and the course of the disease has been estimated from the answers returned. This was made necessary because of the closure of the factory and the scattering of the workers. Answers to the questions were received from 67.9 per cent. : 11.2 per cent. could not be traced through the post, and the rest failed to reply. A small proportion were still without symptoms but others, previously normal, were now suffering attacks. It is estimated that between $\mathbf{7 7 . 3}$ and 90.3 per cent. of the original 278 had now become affected by the disorder. In eleven cases the first symptom had been noticed after exposure to vibration had ceased.

Half of those who had been affected in the first place were of the opinion that their condition was stationary ; 36 per cent. claimed that there had been deterioration in the interim; 4.9 per cent. were improved. One patient, a woman, claimed a spontaneous cure. In spite of small improvements in some cases, the anatomical extent had in the main increased. The workers' present claims to disability have been examined, and their own statements are appended. A number of these statements show evidence of hardship. Disability is claimed only in respect of a hindrance to effective working in certain specified jobs which these people have taken up since. The legal implications of this unusual state of affairs are discussed.

I wish to thank Dr. Donald Hunter, Director of the Department for Research in Industrial Medicine, for the kindness, encouragement, and inspiration he has given me. The Management and Workers of the Firm in question gave their fullest co-operation, and it is a pleasure to record my indebtedness to Dr. M. B. McCann, 
then Senior Works Medical Officer of the Company. Professor E. D. Telford and Dr. F. H. K. Ǵreen kindly gave me very helpful criticism.

\section{APPENDIX}

Statements made by 65 Affected Men and Women in SUPPORT OF THEIR ClAIMS OF DISABILITY FROM ATTACKS of Raynaud's Phenomenon Contracted as a Result of THEIR PREVIOUS OCCUPATION

(Drawn from the questionnaires of September, 1947)

Case 2.-At present a sales clerk. He finds it difficult to concentrate during attacks and had to obtain special permission to have a fire during the fuel cuts of early 1947.

Case 3.-A prepaid electric meter reader who says that he is "handicapped in counting coins during the attacks." This is presumably due to loss of sensation.

Case 4.-A newspaper shop salesman who "cannot handle money during attacks."

Case 6.-A housewife. She claims "Difficulty in washing up and laundering during attacks. I have to wait for them to pass off." She is liable to attacks " several times daily" in winter.

Case 9.-A progress clerk who writes, "Lack of control and speed in writing and filing papers, but my employers have shown great consideration."

Case 14.-A hire-car driver and mechanic. He cannot handle cold spanners or wash down a car without attacks coming on. These jobs have had to be abandoned.

Case 22.-A cloth salesman. In cold weather bedspreads and blankets slip out of his hands when he is showing them to his customers.

Case 25.-Unemployed. He is a man of 57, now unable to dress himself in winter because of the anæsthesia experienced during attacks. He has not worked since 1945 , but considers he would be able to work in summer provided that he does not have to touch bare metal or wet materials.

Case 26.-An assistant spinner who claims that he has " loss of sensitivity in the fingers regardless of attacks."

Case 29.-A housewife who says, "I cannot do washing or clean windows."

Case 32.-A man who is now unemployed. He had got work as a packer but soon had to give it up because the place was too cold and brought on attacks. He is sure that no employer would give him work if he heard about this disability.

Case 34.-A dairyman. $\mathrm{He}$ is a little handicapped by his attacks but remarks, "I don't say anything as I have six children to keep ... very painful and unpleasant in winter.'

Case 37.-A man who has become a fruiterer and who says, "I find work in the winter very difficult, having to wear warm gloves."

Case 38.-Now a french polisher. He is unable to grip anything during attacks.

Case 45.-A man who started as a boiler fireman but had to give up as his shovel flew out of his hand during the attacks. He has now become a postman and states that he cannot feel the letters in his fingers. "When delivering in cold weather, I ask the lady of the house to let me put my hands in warm water."
Case 47.-Now unemployed. He had just given up working as a labourer in a dyeworks because he had to work in water.

Case 53.-A man who has become a bread packer. Normally he handles six loaves at a time, but during attacks he can manage only three.

Case 57.-Now working as a mule spinner. $\mathrm{He}$ is worried because he uses the affected fingers for " piecing up." As the mill is warm, he only has trouble on arriving in the morning. He cannot work till the attack passes off, so in winter he has to arrive "very early" to give time for this to happen.

Case 67.-A man who has become a window dresser, but is hindered because he cannot handle glass shelves or display goods during the attacks, and these come on every day in winter.

Case 68.-Unemployed at present. He finds he " cannot take on a job unless it is in a warm atmosphere and away from water."

Case 69.- This man handles furniture and cannot trust his own grip. He says he is fortunate in having an understanding employer.

Case 78.-A man who is an hotel porter but is liable to drop baggage and crockery during his attacks.

Case 87.-A weaver who has to restore the circulation to her fingers before being able to start work.

Case 90.-A cotton spinner who, during attacks, has difficulty with piecing and taking in rim bands.

Case 96.-A plater's mate who describes in detail how the handling of cold spanners sets off attacks, and how while swinging his 7-lb. hammer he finds it slipping from his grasp. He often has to stop to warm his hands at the rivet fire to restore his circulation.

Case 99.-A man who is a dress cutter. During attacks he cannot handle fabrics, especially silk, because of the loss of sensation.

Case 101.-A man who for twenty-five years of his life has been a polisher of copper rollers. Since leaving the scurfing work he has returned to roller polishing, and finds the cold -metal now brings on attacks of blanching. He fears accidents and will have to give up his only trade at the age of 49 .

Case 102.-A general labourer who complains he cannot now handle a spade.

Case 106.-A metal polisher who has to stop working during attacks.

Case 109.-A cotton operative who, on every winter's day, is behindhand with his work between 7.30 and 9 a.m., at which latter time his fingers return to normal. This chain of events happens in spite of the warm temperature of the mill.

Case 121.-An overlooker in a braiding mill. He complains that his fingers are quite useless for the first thirty minutes of his working day, even in a warm room.

Case 129.-A labourer in concrete, out of doors. His grip is affected during attacks and he cannot handle a spade or wheelbarrow properly; moreover the attacks are painful.

Case 133.-A man who is a roller and boner of bacon. He states, "The bacon is nearly always in frozen condition and when the attack occurs it means I have to slow down until my fingers return to their normal state." 
Case 138. A woollen operative who complains that he cannot change bobbins during an attack.

Case 141.-A radial arm driller. He finds that gripping the cold steel wheel of the drill feed initiates attacks, and these hinder him.

Case 143.-A woodworker who has to stop work to restore the circulation to his fingers. $\mathrm{He}$ is fortunate in being employed at a factory for disabled men.

Case 147.-A window cleaner, called upon to clean outside windows sometimes at a height of 100 feet. $\mathrm{He}$ - is concerned at the loss of sense of touch in attacks.

Case 152.-A fitter's mate on a railway breakdown gang. On going out in wintry weather he finds that the handling of spanners and steel bars brings on attacks, and he has to stop work to warm his hands.

Case 157.-A machine operator who handles small objects. Her work is therefore liable to be hindered in cold weather when she suffers loss of sense of touch.

Case 161a.-A ring spinner who is hindered in taking off bobbins from spindles when she has blanched fingers.

Case 166.-A sheet metal worker. This man cannot hold tools or rivets during attacks and has to take special steps to warm his hands.

Case 167.-A bus driver who says, "If it does not improve in the next few days I shall have to ask to be relieved from driving, as I am afraid of losing control on the road."

Case 168.-A bricklayer. This man has been working indoors but still has attacks. He is incapable of handling bricks with his left hand for about two hours from the start of each attack.

Case 185.- This woman used to be a cook but has lost confidence in the grip of her hand since the attacks started. She is afraid to carry pans of hot water and fat, so she has given up her old job to become a daily cleaner.

Case 187.-Also a cleaner. She has to stop work to massage her fingers during attacks, which come on "often" in the winter.

Case 188.-A cotton spinner who is affected mainly in the left hand, and who happens to use this hand more than the right in her present work. The attacks come on while she is going to work and are terminated by the warmth of the mill.

Case 189.-A plasterer who complains that there are certain jobs he cannot do until the circulation is normal, and he wastes time in trying to restore it.

Case 194.-A man who has found a suitable job in the vulcanizing shop of a rubber works, but who had to give up his previous job as a trainee moulder in a foundry because the damp and cold brought on attacks.

Case 195.-A man who was a packer. He complains that he used to lose the sense of touch during attacks and so became a handyman instead.

Case 204.-A labourer in an electricity undertaking. Being now an outdoor worker he has more frequent attacks which are painful and make "handling" difficult.

Case 205.-A furniture wood stainer. He works with methylated spirit and naphtha, and says he "is like a man with one hand, as the left hand is practically useless."

Case 215.-A labourer in a steelworks. He claims that he dare not take on machine work now because of the vibration which would be involved, so he is " condemned to a weekly loss of $£ 2$ in wages."

Case 220.-A golf-course groundsman who, working out of doors, finds his hands going constantly "dead" and painful, so that it is impossible " to compete with fellow workers."

Case 223.-A cotton mill labourer who works in a cold place in the mill, gets attacks, and "has not the same earning capacity" as before.

Case 227.-A woman who was previously a weaver but who, though, anxious to do so, cannot go back to work because "this is all finger work." She is even hindered in her housework by these attacks.

Case 228.-A joiner who is particularly impeded by not being able to hold nails between finger and thumb during attacks.

Case 233.-A maker-up in a weaving shed who for half an hour each morning finds that cloth is difficult to handle.

Case 236.-A french polisher who is impeded by the deterioration in his " touch." He finds that methylated spirit, with which he works, aggravates the attacks.

Case 238.-A plaster moulder who gets attacks because he constantly has to mix plaster with water by hand.

Case 240.-A girl who used to do hand sewing but cannot return to this. She estimates her weekly loss of earnings is $37 s .6 d$. as a result.

Case 242.-A paperhanger and decorator who cannot hold or feel wallpaper, or handle a brush during the many attacks he has in winter.

Case 255.-A clothing inspector who used to be a tailor but who has had to give this up owing to "loss of grip and feeling" in his hands.

Case 263.-A livery stableman who cannot feel his reins during attacks, which come on several times a day.

Case 274.-A man who is now content as a packer, but who had to give up his previous work as a machine drill operator because his hands were "useless" on arriving at work.

Case 286.-An assembler of agricultural machinery who fears dismissal as soon as his disability is discovered.

\section{REFERENCES}

Agate, J. N., and Druett, H. A. (1946). Brit. J. industr. Med., 3, 159. (1947). Ibid., 4, 141 .

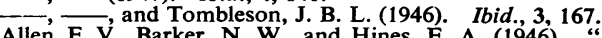

Allen, E. V., Barker, N. W., and Hines, E. A. (1946). " Peripheral Vascular Diseases." W. B. Saunders Co., Philadelphia.

Barker, N. W., and Hines, E. A. (1944). Proc. Mayo Clin., 19, 348

Biden-Steele, K., and King, F. H. (1947). Med. Pr., 218, 144.

Brocklehur

Brocklehurst, T. (1945). Ibid., 213, 10. 129, 668 .

129, 668. tơh, A., Leake, J. P., and others (1918). U.S. Department of Labour, Bureau of Labour Statistics, Bulletin No. 236.

Hunt, J. H. (1936). Quart. J. Med., n.s., 5, 399.

Hunter, D., McLaughlin, A. I. G., and Perry, K. M. A. (1945). Brit. J. industr. Med., $2,10$.

Hutchinson, J. (1901). (Abstract) Med. Pr., 72, 403.

Lewis, T., and Pickering, G. W. (1934). Clin. Sci., 1, 327.

Loriga, G. (1911). Quoted by Teleky, L. "Occupation and Health Supplement," International Labour Office, Geneva, 1938.

Middleton, E. L. (1930). Ann. Rep. H.M. Chief Insp. Fact., p. 119. Mills, J. H. (1942). Northwest Med., 41, 282.

Maynaud, M. (1862). Thesis "On Local Asphyxia and Symmetrical Gangrene of the Extremities." Trans. Barlow, T. (1888), in "Gangrene of the Extremities." Trans. Barlow, T. (1888),

Seyring, M. (1930). Arch. Gewerbepath. Hyg., 1, 359.

Telford, E. D., McCann, M. B., and MacCormack, D. H. (1945). Lancet, $2,359$. 